\title{
Biocompatibility of Regular and White MTA and A Grey Portland Cement in Human Dental Pulp Cells
}

\author{
Cortés Lillo $\mathbf{O}^{1}$, Boj Quesada $\mathbf{J R}^{2}$, Alcaina Lorente $\mathbf{A}^{1, *}$ \\ ${ }^{1}$ Department of Pediatric Dentistry, School of Dental Medicine, University of Murcia, Spain \\ ${ }^{2}$ Department of Pediatric Dentistry, School of Dental Medicine, University of Barcelona, Spain
}

Copyright $(2018$ by authors, all rights reserved. Authors agree that this article remains permanently open access under the terms of the Creative Commons Attribution License 4.0 International License

\begin{abstract}
Currently many materials have been used with pulpotomies in primary teeth. These include MTA, that as a direct pulp capping material seemed to stimulate natural dentin repair at pulpal exposure sites. The composition of this product is based on Portland cement. Later, white MTA was introduced as an esthetic improvement over the original material (grey MTA). A number of studies have been performed on this new material to determine if it shows the same properties as gray MTA. The biocompatibility of MTA has been previously investigated in vitro using a number of the cell lines. However, the use of primary cultures (in this case pulp fibroblasts) is often desirable. Objective: The objective of this in vitro study was to compare the cytotoxicity in a pulp fibroblasts culture, of regular (grey) MTA, white MTA and Portland cement Material and method: A cytotoxicity study was made in a primary pulp fibroblasts culture of MTA, white and grey, and a grey Portland cement. Results: Without taking into account concentrations, there were no significant differences between regular MTA and white MTA $(p=0.146)$. A significant difference was recorded between grey Portland cement, which were less biocompatible, and regular MTA $(\mathrm{p}=0.029)$, and white MTA $(\mathrm{p}=0.002)$. Conclusion: The results found in the present study might be an additional argument to support that MTA is biocompatible, and may be considered as a pulp dressing agent in pulpotomized primary molars with carious pulp exposures. However, the grey Portland cement, under the same conditions, shows reduced biocompatibility.
\end{abstract}

Keywords Biocompatibility, White MTA, Grey MTA, Pulp Cells

\section{Introduction}

The pulpotomy is one of the most frequent treatment in the primary dentition. It consists of the amputation of the coronal pulp affected or infected while the radicular pulp tissue is preserved. The radicular pulp stumps should be covered with a pulpal dressing, and later the tooth is restored. The material to be used for pulpotomies should be bactericidal and harmless to the pulpal tissue and surrounding structures and not interfere with the physiological process of root resorption [1].

Currently many materials have been used with pulpotomies in primary teeth. Formocresol is still the pulp dressing most frequently utilized in clinical practice, but in the last years is being questioned due to its toxic effects. There are different alternatives. These include electrosurgery, laser, ferric sulfate, bone morphogenetic protein and osteogeneic protein [2-5]. The physical and chemical properties of a root-end filling material, mineral trioxide aggregate (MTA) were described by Torabinejad et al [6].

MTA is a powder consisting of tricalcium silicate, dicalcium silicate, tricalcium aluminate, calcium sulfate dehydrate and bismuth oxide. When the material is hydrated, it becomes a colloidal gel that solidifies in approximately 3 hours [7]. Like $\mathrm{Ca}(\mathrm{OH}) 2$, MTA also has a high $\mathrm{pH}(12.5)$ that causes denaturation of adjacent cells, tissues proteins, and some bacteria in the wound area. As the material sets, however, the $\mathrm{pH}$ changes and the cell injuries subside [8]. The set material has low solubility and a radiopacity slightly greater than that of dentin. MTA has been found to have a set compressive strength of about 70 $\mathrm{MPa}$. This is approximately equal to that of IRM [6].

MTA has shown a superior sealing ability compared to amalgam or IRM. Others investigations using MTA as a direct pulp capping material seemed to stimulate natural dentin repair at pulpal exposure sites [9]. It was also found to produce less inflammation and better dentin bridge formation when compared with $\mathrm{Ca}(\mathrm{OH})_{2}$ in monkeys [10].

MTA was found to be biocompatible. In animal studies, MTA was the only material that allowed cementum overgrowth [11]. In vitro studies of human osteoblasts showed that MTA stimuled cytokine release and interleukin production [12]. MTA has been used for many 
clinical treatments. These include successful pulp caps, pulpotomies, apexifications, root perforations repair and root -end filings [13].

Different studies compared MTA's effects as pulp dressing agents in pulpotomized primary molars with carious pulp exposures. Eidelman et al. [14] compared MTA's effects to those of formocresol, and MTA showed clinical and radiographic success as dressing material for pulpotomy in primary teeh. In a long-term clinical a radiographic study, Holan et al. [15] observed that the success rate of pulpotomy was $97 \%$ for MTA, because MTA does not induce undesirable responses. Farsi et al. [16] observed that at the end of a 24 month evaluation period, none of the MTA treated teeth showed any clinical or radiographic success. It was concluded that MTA treated molars showed a significantly greater success. In the histologic study, Agamy et al. [17], showed that grey MTA as a pulp dressing for pulpotomized primary teeth, successfully induced thick dentin bridge formation at the amputation sites and pulp architecture nearest to normal pulp by preserving the odontoblastic layer and a delicate fibrocellular matrix.

Later, white MTA was introduced as an esthetic improvement over the original material (grey MTA). A number of studies have been performed on this new material to determine if it shows the same properties as gray MTA. These studies comparing white and gray MTA have discussed results in terms of biocompatibility, sealing ability and potential to induce tissue regeneration. A leakage study by Ferris and Baumgarnter[18] has shown to have similar properties and Camilleri et al. [19] reported that the osteoblasts had the same biocompatible reaction to both types of MTA. Ribeiro et al., concluded that regular (grey) and white MTA are not genotoxic and do not induce cellular death [20].

Perez et al. [21], in an in vitro study, reported that osteoblastic cell line grown on grey MTA adhered and differentiated better than the cells grown on white MTA. A leakage study by Matt et al. [22], showed that grey MTA demonstrated significantly less dye leakage when compared to white MTA. As a pulp dressing agent, Agamy et al. [17]. conclude that gray MTA is superior to white MTA for pulpotomized primary molars.

Wucherpfenning and Green [23] reported that MTA and Portland cement were almost identical macroscopically and microscopically when evaluated by X-ray diffraction analysis. They reported the formation of reparative dentine when the material was used for direct pulp capping in rat teeth.

Estrela et al. [25] reported that Portland cement contained the same principal chemical elements as MTA, except for bismuth oxide. Saidon et al. [26] concluded that MTA and Portland cement had similar biological properties. Ribeiro et al. [20] demonstrated that MTA and Portland cement had no cytotoxic effects in mouse lymphoma cells. De-Deus et al. [27], showed that Portland cement initially had an elevated cytotoxic effect that decreased gradually with time allowing the cell culture to repair. Camilleri et al. [28] reported that the accelerated Portland cement showed similar results than MTA, with an indirect test method, but cell growth was poor when seeded in direct contact with the cements tested. And De-Deus et al. [29], concluded that Portland cement and MTA demonstrated a similar ability to seal furcal perforations in an in vitro study. The positive biological results achieved with Portland cement were encouraging for its use with lower cost.

The biocompatibility of MTA has been previously investigated in vitro using a number of the cell lines: MG 63 cells, Saos 2 cells, human osteoblasts and L929 fibroblasts $[19,21,30,31$,$] . However, the use of primary$ cultures (in this case pulp fibroblasts) is often desirable, since they may offer increased specific sensitivity to the test agent or substance $[32,33]$.

The objective of this in vitro study was to compare the cytotoxicity in a pulp fibroblasts culture, of regular (gray) MTA, white MTA and Portland cement

\section{Materials and Methods}

The materials used in this study are both variants of MTA, grey MTA and white MTA (Maillefer, Dentsply Tulsa, Tulsa, OK, USA), and a grey Portland Cement (CEM I 52.5 R, Cemex ${ }^{\mathrm{TM}}$, Spain).

Pulp fibroblasts were obtained from healthy premolars extracted for orthodontic reasons. Informed consent was obtained from the patients, and the study was approved by the University of Murcia Ethics Review Committe. After extraction, and avoiding the risk of contamination, each tooth was immersed in a sterile flask containing Dulbecco (DMEM; Gibco Laboratories, Grand Island, NY, USA) culture medium, with streptomycin $(100 \mu \mathrm{gr} / \mathrm{ml})$ and gentamycin $(50 \mu \mathrm{gr} / \mathrm{ml})$ to prevent contamination .

Less than 10 hours later, the pulp tissue was extracted under sterile conditions in a laminar flow chamber. Small fragments of pulp tissue (explants) were then immersed in a culture flask containing DMEM supplemented with $15 \%$ fetal calf serum (FCS; Gibco Laboratories, Grand Island, NY, USA) to stimulate cell proliferation. After harvesting the pulp tissue fragments, the cells were disaggregated using enzyme digestion - in this case type XI collagenase $(1.25 \mathrm{mg} / \mathrm{ml})$ [34].

After separating the cells by centrifugation ( $200 \mathrm{~g}$ for 10 $\min$ ), cell viability was assessed with a hemacytometer based on the trypan blue exclusion test, followed by resuspension in DMEM and incubation.

The culture medium was replaced every two days. Phase contrast light microscopic observations were made to assess cell condition and thus determine the timing of subculture once the cultures reached confluence [35].

The biocompatibility of the test materials was evaluated in vitro according to ISO 10993-part 5 using an indirect testing method. In the indirect test the cytotoxicity of the 
eluant was evaluated.

Methil methalcrylate 2\% (v/v) (Merck, Darmstadt, Germany) (MMA) was used as a positive control. Complete DMEM was tested as negative control. Both variants of MTA were mixed with the liquid provided by the manufacturer. The Portland cement was mixed with water (cement ratio of 0.30 ). The materials were placed into the bottom of culture plates $(3.5 \mathrm{~cm}$ of diameter). The surface area of the test material exposed was $900 \mathrm{~mm}^{2}$. The ratio of surface area exposed to volume of extract vehicle was $64 \mathrm{~mm}^{2} / 200 \mu \mathrm{l}$. Extracts of the test materials were made as follows: $2.8 \mathrm{ml}$ of complete DMEM was placed over each sample and the plates were incubated for $24 \mathrm{hr}$ at $37^{\circ} \mathrm{C}$ and $100 \%$ relative humidity. The medium was then drawn off and sterile-filtered through $0.22 \mu \mathrm{m}$ filter pore size. To observe a dose-response relationship, the extracts were serially diluted at 1:1 with complete DMEM to achieve a total of 5 concentrations of each extract that were then tested for cytotoxicity based on the MTT viability test. The MTT assay shows the effect of a dental material on cell viability by alterations of mitochondrial deshydrogenase activities. Each experiment was performed three times.

\section{Cytotoxicity Testing}

Single cell suspensions of pulp fibroblasts were seeded in 96-well plates, $5 \times 10^{3}$ cells per well in complete DMEM, and incubated in a humidified atmosphere of air and 5\% $\mathrm{CO}_{2}$ at $37^{\circ} \mathrm{C}$ for $24 \mathrm{hr}$. The culture medium was then replaced with $200 \mu \mathrm{l}$ aliquots of the extracts or control media, and the cells thus exposed were incubated for $24 \mathrm{hr}$, at $37^{\circ} \mathrm{C}$ under humidified air and $5 \% \mathrm{CO}_{2}$, like recommended extracts condition in ISO 10993 -5 [22]. After exposure, cell viability was determined by the ability of the cells to transform the tetrazolium salt (MTT; Sigma Chemical Co. St Louis, MO, USA) into a formazan. MTT was dissolved in phosphate buffered saline and $50 \mu \mathrm{l}$ of the solution were added to $200 \mu \mathrm{l}$ complete culture medium. The cells were incubated for $3 \mathrm{hr}$. At $37^{\circ} \mathrm{C}$. the MTT solution was disared. Traces of medium were removed and formazan crystals got diluted with $200 \mu$ l dimethyl sulfoxide. The absorbance of each well was determined using an automatic microplate spectrophotometer at 550 $\mathrm{nm}$.

Mean absorbance values obtained for each concentration were calculated as a percentage of the mean negative control value (set as $100 \%$ viability). Differences in mean cell viability values between materials were assessed by a Mann-Whitney test, involving application of equal mean pairs contrast with the minimum significant difference method $(\mathrm{p}<0.05)$.

\section{Results}

The highest extract concentration for all test materials give cell viability values that were not significant different from the positive control (Methil methalcrylate 2\%).

For the two lowest concentrations tested $(1 / 16,1 / 8)$, no difference was found between each material, given cell viability values that were not significantly different from the negative control (Complete DMEM; 100\% viability) (figure 1).

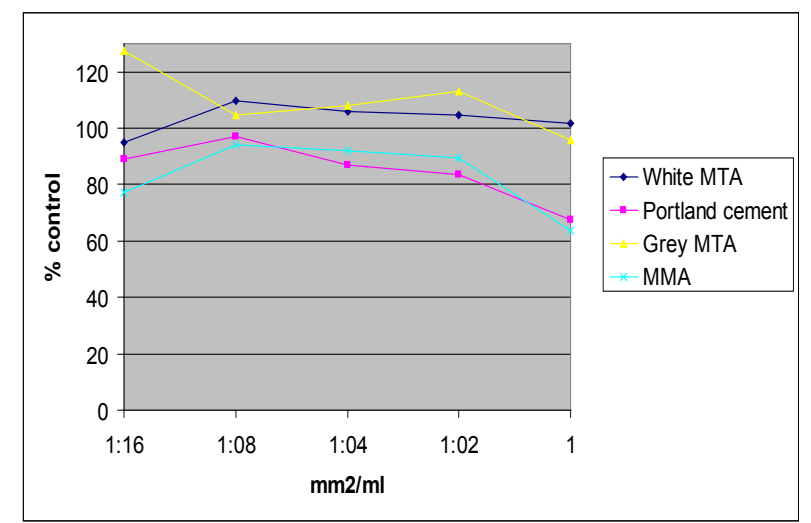

Figure 1. Cell viability values for concentrations of all materials.

Without taking into account concentrations, there were no significant differences between regular MTA and white MTA $(\mathrm{p}=0.146)$. A significant difference was recorded between gray Portland cement, which were less biocompatible, and regular MTA $(p=0.029)$, and white MTA ( $\mathrm{p}=0.002)$.

Thus, all materials, when tested undiluted, exhibited a cytotoxic effect (Portland cement being more cytotoxic than the other materials), while, as expected, cytotoxicity progressively decreased with dilution; for the lowest concentrations of all materials, the viability values were no different from those of the negative control $(100 \%$ viability).

\section{Dicussion}

This study was conducted using material extracts rather than by direct material application to the cells. Eluates allows to observe a possible dose response relationship and determine the most ideal concentration for the sensitivity of the cells tested. We thus adopted as reference the ISO norms for the biological evaluation of the materials based on in vitro cytotoxicity testing [36].

Previous studies of the cytotoxicity of MTA have been based on the use of established cell lines. Established cell lines obtained from collections allows increased reproducibility of the results and are recommended by the ISO for preliminary cytotoxicity screening. However, the use of primary cultures (in this case pulp fibroblasts) is often desirable and also recommended by the ISO, since they may offer increased specific sensitivity to the test agent, because they partly simulate the biological conditions under which such agents are used, and cell 
viability and functionality are the habitually evaluated Parameters $[32,36]$.

Our results confirm the data already published showing the good biocompatibility of MTA. No difference was observed in this study between grey MTA and white MTA, like Ribeiro et al. [20], and Camilleri et al. [19]. On the other hand, Perez et al. [21] showed that the grey variant was more biocompatible. However, Oviir et al [37] suggested that white MTA was more biocompatible than gray MTA in supporting human cementoblast and keratinocyte growth. Others studies used pulp fibroblasts culture [24].

The biocompatibility of some types of Portland cements is evaluated in several studies [25]. A study comparing MTA and Portland cement containing varying rations of bismuth oxide on immortalized human periodontal ligament cells showed that Portland cement without the addition of bismuth oxide has the same level of cell viability as MTA at 12 and 24 hours. The addition of bismuth oxide to Portland cement powder at all ratios in this study significantly lowered cell viability during early evaluation time [38].

Previous studies showed that Portland cement has the same physical, chemical and biological properties than MTA, and similar biocompatibility. Camilleri et al. [19] compared different Portland cements. Their results showed that cell growth was poor when seeded in direct contact with the test cements (gray Portland cement and white Portland cement). Calcium hydroxide induced cell proliferation during the hydration reaction. Some authors have reported that MTA and Portland cement release calcium ions when they are in contact with tissue fluid, thus promoting an alkaline $\mathrm{ph}$. This hydration produces calcium silicate hydrate gel and calcium hydrate, which would explain why MTA, Portland cement, and calcium hydroxide provoke the same tissue reaction [39].

In a study on the primary teeth of pigs, Shayegan et al [40] compared white MTA with ferric sulfate, formocresol, beta-tricalcium phosphate cement, and white Portland cement as a pulp capping agent. Their findings showed no significant differences between beta-tricalcium phosphate, white MTA, and Portland cement in terms of primary pulp response, hard tissue formation, and normal pulp tissue preservation. between any of the materials. In our study, gray Portland cement showed less biocompatibility than both MTA cements. The differences between particle size of materials (gray Portland cement had the largest particles) that would explain the differents results.

\section{Conclusions}

The results found in the present study might be an additional argument to support that MTA is biocompatible, and may be considered as a pulp dressing agent in pulpotomized primary molars with carious pulp exposures. However, the grey Portland cement, under the same conditions, shows reduced biocompatibility. Futher studies using newer Portland cements are recommended taking also into consideration that cytotoxicity is only a part of pulp biocompatibility - the latter also depending on other aspects such as marginal sealing and bacterial microleakage. Clinical studies are thus also required to assess pulp response to these materials.

\section{REFERENCES}

[1] American Academy of Pediatric Dentistry. Guideline on pulp therapy for primary and young permanent teeth. Pediatr Dent 2008; 30: 170-174.

[2] Ranly DM. Pulpotomy therapy for primary teeth: new modalities for old rationales. Pediatr Dent 1994; 16: 403-409.

[3] Fei AL, Udin RD, Johnson R. A clinical study of ferric sulfate as a pulpotomy agent in primary teeth. Pediatr Dent 1991; 13: 327-332.

[4] Cortés D, Boj JR, Canalda C et al. Pulpal tissue reaction to formocresol vs. ferric sulfate in pulpotomized rat teeth. J Clin Pediatr Dent 1997; 21: 247-253.

[5] Rutherford RB, Wahle J, Tucke M et al. Induction of reparative dentine formation in monkeys by recombinant human osteogenic protein-1. Arch Oral Biol 1993; 38: 571-576

[6] Torabinejad M, Hong CU, Mc Donald F et al. Physical and chemical properties of a new root-end filling material. J Endod 1995; 21: 349-353.

[7] Schwartz RS, Mauger M, Clement DJ et al. Mineral trioxide aggregate: A new material for endodontics. J Am Dent Assoc 1999; 130: 967-75.

[8] Saidon J, He J, Zhu Q et al. Cell and tissue reactions to mineral trioxide aggregate and Portland cement. Oral Surg Oral Med Oral Pathol Oral Radiol endod 2003; 95: 483-9.

[9] Faraco IM, Holland R. Response of the pulp of dogs to capping with mineral trioxide aggregate or a calcium hydroxide cement. Dent Traumatol 2001; 17: 163-6.

[10] Pitt Ford T, Torabinejad M, Abedi $\mathrm{H}$ et al. Using mineral trioxide aggregate as a pulp-capping material. J Am Dent Assoc 1996; 127: 1491-4.

[11] Torabinejad M, Pitt Ford TR, McKendry DJ et al. Histologic assessment of MTA as a root-end filling in monkeys. J Endod 1997; 23 225-8

[12] Koh ET, McDonald F, Pitt Ford TR et al. Cellular response to mineral trioxide aggregate. J Endod 1998; 24:543-7.

[13] Salako N, Joseph B, Ritwik P et al. Comparison of bioactive glass, mineral trioxide aggregate, ferric sulfate, and formocresol as pulpotomy agents in rat molar. Dent Traumatol 2003;19:314-20.

[14] Eidelman E, Holan G, Fuks A. Mineral trioxide aggregate vs formocresol in pulpotomized primary molars: A preliminary 
report. Pediatr Dent 2001; 23: 13-15

[15] Holan G, Eidelman E, Fuks A. Long term evaluation of pulpotomy in primary molars using mineral trioxide aggregate or formocresol. Pediatr Dent 2005; 27: 129-136.

[16] Farsi N, Alamoudi N, Balto K et al. Success of mineral trioxide aggregate in pulpotomized primary molars. J Clin Pediatr Dent 2005; 29: 307-11.

[17] Agamy H, Bakry N, Mounir M et al. Comparison of mineral trioxide aggregate and formocresol as pulp-capping agents in pulpotomized primary teeth. Pediatr Dent 2004; 26: 302-9.

[18] Ferris DM, Baumgartner JC. Perforation repair comparing two types of mineral trioxide aggregate. J Endod 2004; 30: 422-4.

[19] Camilleri J, Montesin F, Papaioannou S et al. Biocompatibility of two commercial forms of mineral trioxide aggregate. Int Endod J 2004; 37: 699-704.

[20] Ribeiro DA, Matsumoto MA, Duarte MA et al. Ex vivo biocompatibility tests of regular and white forms of mineral trioxide aggregate. Int Endod J 2006; 39: 26-30.

[21] Perez AL, Spears R, Gutmann JL et al. Osteoblasts and MG-63 osteosarcoma cell behave differently when in contact with ProRoot MTA and White MTA. Int Endod J 2003; 36: 564-9.

[22] Matt GD, Thorpe JR, Strother JM et al. Comparative study of white and gray mineral trioxide aggregate stimulating a one or two step apical barrier technique. J Endod 2004; 30 : 876-9.

[23] Wucherpfenning AL, Green DB. Mineral trioxide vs Portland cement: two biocompatibile filling materials. J Endod 1999; 25: 308 (Abstract)

[24] Keiser K, Johnson CC, Tipton DA. Cytotoxicity of mineral trioxide aggregate using human periodontal ligament fibroblasts. Journal of Endodontics. 2000 May $1 ; 26(5): 288-91$.

[25] Estrela C, Bammann LL, Estrela CR et al. Antimicrobial and chemical study of MTA, Portland Cement, calcium hydroxide paste, Sealapex and Dycal. Braz Dent J 2000; 11 : 3-9.

[26] Saidon J, He J, Zhu Q et al. Cell and tissue reactions to mineral trioxide aggregate and Portland cement. Oral Surg, Oral Med, Oral Pathol, Oral Radiol and Endod 2003; 95: 483-9.

[27] De-Deus G, Ximenes R, Gurgel -Filho E et al. Cytotoxicity of MTA and Portland cement on human ECV 304 endothelial cells. Int Endod J 2005; 38: 604-9.

[28] Camilleri J, Montesin F, Di Silvio L et al. The chemical constitution and biocompatibility of accelerated Portland cement for endodontic use. Int Endod J 2005; 38: 834-42.

[29] De-Deus G, Petruccelli V, Gurgel -Filho E et al. MTA versus Portland cement as repair material for furcal perforations: a laboratory study using a polymicrobial leakage model. Int Endod J 2006; 39: 293-98.

[30] Mitchell P, Pitt Ford TR, Torabinejad M et al. Osteoblast biocompatibility of mineral trioxide aggregate. Biomaterials
1999; 20:167-73.

[31] Haglund R, He J, Jarvis J, et al. Effects of root-end filling materials on fibroblasts and macrophages in vitro. Oral Surg, Oral Med, Oral Pathol, Oral Radiol and Endod 2003; 95: 739-45.

[32] Van WyK CW, Olivier A, Maritz JS. Cultured pulp fibroblasts : are theysuitable for in vitro cytotoxicity testing?. J Oral Pathol Med 2001; 30: 168-77.

[33] Cortés O, García C, Perez L. Pulp cell cultures obtained with two different methods for in vitro cytotoxicity tests. Eur Arch Paediatr Dent 2006; 7(2): 96-9.

[34] Jakoby WB, Pastan IH. Cell culture methods in enzymology. Academic Press INC. California 1979.

[35] International Standards Organization.1992.10993-5. Biological evaluation of medical devices. Part 5. Tests for citotoxycity: in vitro methods.

[36] Feigal, RJ, Yesilsoy C, Messer, HH et al. Differential sensitivity of normal human pulp and transformed mouse fibroblasts to cytotoxic challenge. Arch Oral Biol 1985; 30: 609-13.

[37] Oviir T, Pagoria D, Ibarra G et al. Effects of gray and White mineral trioxide agrégate on the proliferation of oral keratinocytes and cementoblasts. J Endod 2006; 32: 210-3.

[38] Kim EG, Lee BC, Chang HS et al. Evaluation of the radiopacity and cytotoxicity of Portland cements containing oxide. Oral Surg Oral Med Oral Pathol Oral Radiol Endod 2008; 105: 54-7.

[39] Holland R, Souza V, Nery MJ et al. Reaction of rat connective tissue to implanted dentin tube filled with mineral trioxide aggregate or calcium hydroxide. Endod J 1999; 25: 161-6.

[40] Shayegan A, Petein M, Vanden A. Beta-tricalcium phosphate, white mineral trioxide aggregate, white Portland cement, ferric sulfate, and formocresol used as pulpotomy agents in primary pig teeth. Oral Surg Oral Med Oral Pathol Oral Radiol Endod 2008; 105: 536-42. 